\title{
Ultrasonography compared with intravenous urography in investigation of urinary tract infection in adults
}

\author{
John Spencer, David Lindsell, Irene Mastorakou
}

\begin{abstract}
Objective-To compare ultrasonography with intravenous urography for investigating adults with proved urinary tract infection.

Design-Prospective study of patients presenting consecutively for radiological investigation of urinary tract infection between October 1988 and December 1989. Both investigations were performed concurrently and performed independently on routine lists by different duty radiologists, each of whom knew the details on the request form but not the findings of the other investigation.
\end{abstract}

Setting-Radiology department of a teaching hospital.

Patients -158 Consecutive adults (89 women, 69 men; mean age 49.7 (range 18-83)) referred from general practitioners and hospital outpatient clinics with a history of proved urinary tract infection.

Interventions-Urography and ultrasonography performed concurrently. When both examinations gave normal findings no clinical or radiological follow up was sought. All abnormal findings detected with either investigation were confirmed by subsequent imaging studies or by operative procedures.

Main outcome measure-Accuracy of detection of abnormalities of urinary system by ultrasonography compared with urography.

Results-113 Patients (72\%) had normal urographic and ultrasonic findings. Overall, ultrasonography concurred with the findings of urography in $149(94 \%)$ patients, and when a single abdominal radiograph was included in the procedure, in 152 $(96 \%)$. Ultrasonography missed only one important diagnosis, that of mild papillary necrosis in normal sized kidneys in a diabetic patient. It detected one early bladder tumour not visible on urography and was able to clarify the nature of renal masses (simple cysts) evident on three urograms.

Conclusion-Ultrasonography provides a safe and accurate method of imaging the urinary tract in adults with infection. Combined with a plain abdominal radiograph, it should replace urography as the initial imaging investigation in these patients. Major savings would result from adopting this policy, and the risks to patients from ionising radiation and intravenous contrast media would be appreciably reduced.

Department of Radiology Oxford OX3 9DU

John Spencer, FRCR, senior registrar in radiology

David Lindsell, FRCR, consultant radiologist

Irene Mastorakou, $\mathrm{MD}$, research fellow

Correspondence to: $\mathrm{Dr}$ Spencer.

BrMed f 1990;301:221-4 is usually combined with a plain abdominal radiograph to detect small urinary calculi. Ultrasonography has proved to be accurate and safe and is well tolerated in this group of patients. In addition to an important reduction in the dose of ionising radiation and avoiding the risks of reactions related to contrast media, there have been appreciable savings in the cost and examination time per pätient. The efficacy of ultrasonography in investigating adults with urinary tract infection does not seem to have been formally established. We therefore conducted a prospective comparative study of the accuracy of ultrasonography compared with urography in adults referred for investigation of urinary tract infection.

\section{Patients and methods}

One hundred and fifty eight consecutive patients ( 89 women and 69 men) referred from either general practitioners or outpatient departments of this hospital with a history of recorded urinary tract infection and a request for urography or ultrasonography were entered into the study. In most cases the request was solely for urography. The patients attended this hospital between October 1988 and December 1989. Their age ranged from 18 to 83 years (mean 49.7 years), 94 of them being aged under 50 . Of the 158 patients, $115(73 \%)$ were referred by general practitioners. They were sent a routine appointment for urography with an explanation that ultrasonography would also be performed. All bookings were made for the routine outpatient lists, and in all patients the investigations were performed concurrently.

A mild laxative was given the night before their urography investigation and patients were starved from midnight. The examination was performed by the duty radiologist. A full length abdominal radiograph was taken initially with supplementary views when appropriate. An intravenous injection of either meglumine and sodium diatrizoate $(325 \mathrm{~g}$ iodine $/ \mathrm{l})$ or iopamidol $(300 \mathrm{~g} / \mathrm{l})$ was given at a dose of $1 \mathrm{ml} / \mathrm{kg}$ body weight. Immediately after the injection an upper abdominal (cross kidney) radiograph was taken followed by a similar radiograph five minutes after injection. (At the discretion of the supervising radiologist tomograms of the renal area were made or abdominal compression was applied after inspection of these initial radiographs.) A full length abdominal radiograph was taken about 20 minutes after injection, with a view of the bladder when filled. The patient was then taken for ultrasonography and on return a bladder radiograph was obtained after micturition. For ultrasonography the patient was examined on the routine list by the duty radiologist with either an Accuson 128 or an ATL Ultramark 4 machine with a $3.5 \mathrm{MHz}$ sector scanning transducer. A routine transabdominal examination of the urinary tract was made with the patient in the supine and oblique positions before the patient returned for completion of the urogram. The bladder was not filled specifically for ultrasonography.

The two investigations were reported independently, and the results that we used for comparison were those in the reports issued to the referring clinician. If the 
clinical assessment, urography, and ultrasonography all gave normal results and no further investigations were planned we assumed a diagnosis of 'normal.' When the two investigations agreed as to the nature of the abnormalities and no further investigations were indicated we accepted the diagnosis. If a discrepancy was found the investigations were reviewed and an eventual diagnosis was based on additional clinicopathological data or imaging studies, or both, on findings at cystoscopy or during other operative procedures, when performed.

\section{Results}

Among the patients examined, $113(72 \%)$ had entirely normal findings on urography and ultrasonography. Table I gives details of the abnormalities shown by urography. A total of 50 abnormalities was found in 45 patients, but in eight patients the urogram was unable to define the exact nature of the abnormality (four showed unexplained mild unilateral hydronephroses, three showed renal space-occupying lesions, and one showed bilateral mild hydroureters). The most common abnormal finding was prostatic hypertrophy and in all cases the referring doctor had suggested this as the most probable diagnosis based on clinical findings.

TABLE I-Findings on urography in 158 adult patients referred for investigation of urinary tract infection

\begin{tabular}{lc}
\hline & No of patients \\
\hline Normal findings & 113 \\
Prostatic hypertrophy with or without bladder trabeculation & $11(7)^{\star}$ \\
Renal calculi & 10 \\
Unilateral mild hydronephrosis (unexplained) & 4 \\
Duplex kidney & 4 \\
Renal space-occupying lesion & 3 \\
Small bladder diverticulum & 3 \\
Small scarred kidneys & 3 \\
Unilateral hydroureter due to calculus & 2 \\
Absent kidney & 2 \\
Irregular bladder wall & 2 \\
Unilateral mild papillary necrosis & 1 \\
Sclerotic bony metastases (prostatic) & 1 \\
Obstruction at pelviureteric junction & 1 \\
Bladder stone & 1 \\
Ureterocele with hydroureter & 1 \\
Mild bilateral hydroureter (unexplained) & 1 \\
\hline
\end{tabular}

${ }^{\star}$ In four patients this finding was not reported but was evident on review.

TABLE II-Abnormalities in 13 patients in whom detailed findings on urography and ultrasonography differed

\begin{tabular}{lc}
\hline Abnormality & No of patients \\
\hline On urogram alone: & \\
Duplex kidney & 3 \\
Small bladder diverticulum (with enlarged prostate) & 2 \\
Papillary necrosis & 1 \\
Mild bilateral hydroureter (unexplained) & 1 \\
Ureteric calculi & $2 \dagger$ \\
Renal calculi & $2 \dagger$ \\
Sclerotic metastases (with enlarged prostate) & $1 \dagger$ \\
On ultrasonography alone: & 1 \\
Bladder tumour &
\end{tabular}

${ }^{\star}$ Ultrasonography showed upper tract dilatation alone in one patient. †Abnormality visible on plain radiograph.
Ultrasonography alone was able to show 39 of the 50 abnormalities $(78 \%)$ shown by urography and when it was combined with a single plain abdominal radiograph this proportion increased to $43(86 \%)$ with only one important diagnosis being missed (mild unilateral papillary necrosis). In 36 of the 45 patients with abnormalities we found that, although both investigations detected the same abnormalities, one or other was superior for delineating the abnormality. Eight patients had normal ultrasonography but abnormal urography, and one patient had abnormal ultrasonography but normal urography. Table II shows the details of cases in which urographic and ultrasonic findings differed. In addition to clarifying the nature of the three renal space-occupying lesions shown on urograms (simple cysts), ultrasonography showed a small bladder tumour that had been missed by urography. (It also detected in passing several important abnormalities in other organs, including abdominal aortic aneurysms, ovarian cysts, and gallstones, and it detected several incidental small renal cysts.)

In the 94 patients aged under 50 (52 women and 42 men) there was a slightly higher proportion of patients with normal findings on both examinations (71/94, $76 \%)$ compared with that in the older group (42/64, $66 \%$ ). In the young patients ultrasonography and a plain abdominal radiograph did not miss any important abnormalities when compared with urography. Of the young men, 14 (33\%) had abnormal findings on urography compared with only nine $(17 \%)$ of the young women. Table III gives the number of abnormal findings for patients subdivided by sex and age.

Overall, ultrasonography combined with a single abdominal radiograph concurred with the findings of urography in 152 of the 158 patients studied (96\%).

\section{Discussion}

The low yield of important abnormalities of the urinary tract found by urography in this study is similar to that found by other prospective studies. Studies of young women investigated for recurrent urinary tract infections showed that about $90 \%$ had an entirely normal urogram, with another $5 \%$ showing only minor normal anatomical variants. ${ }^{3.5}$ The remaining small proportion of abnormal urograms showed a roughly equal mixture of abnormalities resulting from prior infection (scarring and atrophy) and of findings that might have influenced management. The number of young women referred for investigation of urinary tract infection by urography has fallen with the recognition of these findings. In a similar survey in the United Oxford Hospitals in 1970-1, 76\% of those referred for investigation by urography were women compared with $56 \%$ in our study. ${ }^{6}$ Interestingly, the overall rate of normal findings was $71 \%$, which is almost identical with ours, though the earlier study did not analyse findings by sex or age.

Studies including elderly men have shown a high incidence of abnormalities on urography relating to the causes and effects of bladder outflow obstruction. In

TABLE III - Findings on urography and ultrasonography with plain abdominal radiograph for 158 patients with history of urinary tract infection, analysed by sex and age. Figures are numbers of patients

\begin{tabular}{|c|c|c|c|c|}
\hline Age (years) & $\begin{array}{l}\text { Normal findings on urography } \\
\text { and ultrasonography with } \\
\text { plain abdominal radiograph }\end{array}$ & $\begin{array}{l}\text { Abnormal findings } \\
\text { on urography }\end{array}$ & $\begin{array}{l}\text { Abnormal findings on } \\
\text { ultrasonography with plain } \\
\text { abdominal radiograph }\end{array}$ & Total No (\%) with abnormality \\
\hline \multicolumn{5}{|c|}{ Men } \\
\hline$<50(n=42)$ & 28 & 14 & 13 & $14(33)$ \\
\hline$\geqslant 50(n=27)$ & 14 & 13 & 12 & $13(48)$ \\
\hline \multicolumn{5}{|c|}{ Women } \\
\hline$<50(\mathrm{n}=52)$ & 43 & 9 & 8 & $9(17)$ \\
\hline$\geqslant 50(n=37)$ & 28 & $8^{\star}$ & 7 & $9(24)$ \\
\hline Total & 113 & 44 & 40 & 45 \\
\hline
\end{tabular}

^One small bladder tumour missed. 
one such series $84 \%$ had abnormal urograms with more than half having established prostatic disease and over $80 \%$ requiring instrumentation. ${ }^{7}$ When men with a history of bladder outflow obstruction were excluded the proportion of abnormal urograms fell to $22 \%$ with less than half of the abnormalities affecting further investigation and management. ${ }^{8}$ The proportion and range of abnormalities shown by urography in our study $(33 \%, 14 / 42$ for men aged $<50 ; 48 \%, 13 / 27$ for men aged $\geqslant 50$ ) were a reflection of the unselected population that we studied. We believe that our study population was a representative cross section of men who had been sent for further investigation by most departments.

Our study showed that ultrasonography is a sensitive and accurate method of investigating the mixed population of adults referred with a history of proved urinary tract infection to a busy radiology department. The findings concurred with those on urography in 149 (94\%) of the 158 patients. Table IV summarises the overall agreement between the two examinations.

TABLE IV-Overall agreement between urography and ultrasonography (158 patients)

\begin{tabular}{lc}
\hline Finding & No of patients \\
\hline $\begin{array}{l}\text { Normal, ultrasonography; normal, urography } \\
\text { Abnormal, ultrasonography; abnormal, urography (same }\end{array}$ & 113 \\
$\quad$ abnormality detected & 36 \\
Normal, ultrasonography; abnormal, urography & 8 \\
Abnormal, ultrasonography; normal, urography & 1
\end{tabular}

$\star$ Better delineated by one or other method.

†In four additional patients urography showed additional abnormalities over ultrasonography alone.

When ultrasonography was combined with an abdominal radiograph accuracy was increased to 152 (96\%). Most of the false negative findings on ultrasonography occurred in patients in whom urography was able to show abnormalities in non-dilated pelvicaliceal systems; three patients had incomplete duplex systems that were not apparent on ultrasonography (but did not affect patient management) and one had mild papillary necrosis. This patient was an established diabetic patient in whom the kidneys were of normal size without cortical scarring.

Ultrasonography cannot image most of the normal ureter and therefore fails to detect most ureteric calculi, although it will show any secondary proximal ureteropelvic dilatation if present. In our study two ureteric calculi were not visualised with ultrasonography alone. Patients with acute loin pain were not included in our series. Urography has been shown to be superior to ultrasonography in this situation, principally because ultrasonography relies on secondary obstructive dilatation as an indicator of ureteric calculi. ${ }^{9}$ In eight out of the 10 patients with renal calculi these were correctly diagnosed on ultrasonography. The efficacy of this investigation in assessing renal calculi has been established and it relates to the size of the calculi. ${ }^{10} \mathrm{We}$ therefore recommend that in addition to ultrasonography a single abdominal radiograph is obtained in adults investigated for urinary tract infection, which is the established policy in children.

We found that ultrasonography was considerably better than urography for evaluating the prostate gland, as has been found by others. ${ }^{112}$ The bladder was not filled to the degree usual in the scanning of pelvic organs and no images after voiding were obtained. Ultrasonography was at a relative disadvantage in this respect and failed to show two small bladder diverticula that were evident only in the urograms after voiding. It did, however, diagnose a small bladder tumour not seen on urography. Several incidental renal cysts were evident only on ultrasonography, and in three patients the urogram showed only a renal space-occupying lesion that required further clarification by ultrasonography.

The indications for imaging of the urinary tract in adults with urinary tract infection remain a matter of debate and controversy. Most authorities now see no role for the radiological investigation of young women with uncomplicated recurrent infections. ${ }^{13}$ An episode of acute pyelonephritis or haematuria or a history of childhood infection, stones, or obstructive symptoms increases the likelihood of an underlying remediable abnormality. ${ }^{414}$ The need to investigate men at all ages has recently been reiterated and is further emphasised by our results, particularly in young men. ${ }^{15}$

The dependence of ultrasonography on the operator is well recognised, and therefore any change in imaging protocol will depend on local skill. In our study the ultrasonography was performed by several different operators with varying experience, and therefore our results do not reflect solely the skill of a single radiologist with a particular interest in ultrasonography.

We thus advocate that when imaging of the urinary tract in either sex is indicated or required the initial evaluation should be by ultrasonography supplemented by a plain abdominal radiograph. Patients would benefit because they would have a shorter, noninvasive investigation without loss of diagnostic accuracy and in addition would be less exposed to the hazards of ionising radiation and intravenous contrast media. Considerable savings on the cost of contrast media, injection materials, and $x$ ray film would ensue, particularly in view of the increasing use of the more expensive non-ionic contrast media. ${ }^{16}$ The potential savings that may be made by each department will vary. The consumable costs of an intravenous urogram (film, contrast media, and injection materials) have been conservatively estimated to be $£ 25$ compared with $£ 1$ for an ultrasound examination, ${ }^{16}$ and even if a single abdominal radiograph is also taken the time savings for radiologists and radiographers will be considerable. Based on these conservative costings, over $£ 3500$ would have been saved on consumables alone if the 158 patients in our study had been investigated with ultrasonography and a plain abdominal radiography instead of urography.

Urography will be required for further elucidation of abnormalities detected on ultrasonography in a small proportion of patients with urinary tract infection and will remain the best imaging study for investigating sterile pyuria.

We thank all our colleagues who performed investigations and Mr G Fellows, Mr J Smith, and Dr E W Fletcher for their helpful advice on the manuscript .

1 Alon U, Menucha P, Davidai G, Berant M. Ultrasonography in the radiological evaluation of children with urinary tract infection. Pediatrics 1986;78:58-64.

2 Lindsell D, Moncrieff D. Comparison of ultrasound examination and intravenous urography after urinary tract infection. Arch Dis Child 1986;61:81-3.

3 Engel G, Schaeffer AJ, Grayhack JT, Wendel EF. The role of excretory urography and cystoscopy in the evaluation and management of women with recurrent urinary tract infection. $f$ Urol 1980;123:190-1.

4 Fair WR, McLennan BL, Jost RG. Are excretory urograms necessary in evaluating women with urinary tract infection? f U Urol 1979;121:313-5.

5 Fowler JE, Pulaski ET. Excretory urography, cystography and cystoscopy in the evaluation of women with urinary tract infection: a prospective study. NEngl F Med 1981;304:462-5.

6 Fletcher EWL, Stephenson RH. The findings reported in patients undergoing excretory urography for recurrent urinary tract infection. $\mathcal{J} R$ Coll Gen Prac 1975;25:146-50.

Lipsky BA. Urinary tract infections in men. Epidemiology, pathophysiology diagnosis, and treatment. Ann Intern Med 1989;110:138-50.

8 Booth CM, Whiteside CG, Milroy EJG, Turner-Warwick RT. Unheralded urinary tract infection in the male. A clinical and urodynamic assesment. BrF Urol 1981;53:270-3.

9 Hill MC, Rich JI, Mardiat JG, et al. Sonography versus excretory urography in acute flank pain. $A 7 R$ 1985;144:1235-8.

10 Middleton WD, Dodds WJ, Lawson TL, Foley WD. Renal calculi: sensitivity for detection with US. Radiology 1988;167:239-44.

11 Lucas MG, Bodley RN, Lindsell DRM, Fletcher EWL, Scott NP. Urography prior to prostatectomy. Postgrad Med f 1986;62:1117-9. 
12 Fidas A, McKinley J, Wild SR, Chisholm GD. Ultrasonography as a alternative to intravenous urography in prostatism. Clin Radiol 1987; 38:479-81.

13 DeLange EE, Jones B. Unnecessary intravenous urography in young women with recurrent urinary tract infections. Clin Radiol 1983;34:551-3.

14 Kanel KT, Kroboth FJ, Schwentker FN, Lecky JW. The intravenou pyelogram in acute pvelonephritis. Arch Intern Med 1988;148:2144-8.
15 Gower PE. Urinary tract infections in men. Investigate at all ages. $\mathrm{Br}$ Med $\mathcal{J}$ 1989:298: 1595-6.

16 Lewis-Jones HG, Lamb GHR, Hughes PL. Can ultrasound replace the intravenous urogram in the preliminary investigation of renal tract disease? Br F Radiol 1989;62:977-80.

\title{
For Debate
}

\section{Radiotherapy for ductal carcinoma in situ detected by screening}

\author{
C R Hamilton, R B Buchanan
}

The national screening programme for breast cancer has led to women with asymptomatic ductal carcinoma in situ being detected and referred for treatment. This condition has an apparently excellent prognosis, but no precedent regarding treatment exists. A study in the United Kingdom has commenced comparing four treatments in patients with asymptomatic ductal carcinoma in situ (protocol available from the Cancer Research Campaign Clinical Trials Centre, Rayon Institute, London SE5 9NU). The four treatments comprise complete local excision alone, complete local excision plus tamoxifen, complete local excision plus radiotherapy, and complete local excision plus tamoxifen and radiotherapy. The trial will be a prospective randomised study incorporating a $2 \times 2$ factorial design, which permits evaluation of each additional treatment (figure). Participating doctors who think that either radiotherapy or tamoxifen is an essential or unacceptable treatment will be able to enter women in single randomisations for only one half of the trial. Can the use of radiotherapy be justified in this study when the course of the disease is poorly understood, the survival of patients is not in question, and serious doubts about the later effects of radiation exist?

In 1932 Broders defined carcinoma in situ as "a condition in which malignant epithelial cells and their progeny are found in or near positions occupied by their ancestors before the ancestors underwent malignant transformations."' Under a light microscope ductal carcinoma in situ appears as a carcinoma of mammary ducts in which there is no evidence of invasion through the basement membrane into the surrounding stroma. ${ }^{2}$ An important problem, however, is that failure to show invasion into the stroma by microscopy does not mean that none is present, and careful histological examination of several sections is necessary before the condition can be diagnosed.

In the past patients with ductal carcinoma in situ presented with a mass in the breast and were managed by mastectomy. This approach was supported by the $60 \%$ incidence of residual ductal carcinoma in situ, ${ }^{3}$

BrMed J 1990;301:224-5 the $6-18 \%$ incidence of invasive carcinoma found in mastectomy specimens, ${ }^{34}$ and the virtually $100 \%$ rate of cure after such surgery. ${ }^{5}$ Even so, some patients have been managed less aggressively, and in a group of 25 women managed only by biopsy $28 \%$ developed invasive cancer within three to 10 years after biopsy. ${ }^{6}$ When recurrence or invasive cancer develops, it tends to do so at or near the site of the original lesion, and provided that the patient is being carefully monitored such developments do not seem to prejudice survival. This point is of such importance as to have been the subject of a national survey by the American College of Surgeons, which found no statistical difference in five year rates of cure and survival when comparing 202 patients with ductal carcinoma in situ managed initially either by mastectomy or by less aggressive procedures. ${ }^{7}$ Similar conclusions were drawn in a smaller British study of 28 cases. ${ }^{8}$

If the survival of women with ductal carcinoma in situ is not in doubt the justification for irradiation must be a reduction in the rate of local recurrence or in the development of invasive cancer. Some evidence exists suggesting that such reductions occur. In the national surgical adjuvant breast project 78 women with ductal carcinoma in situ were identified from the 2072 patients with invasive cancer enrolled. ${ }^{9}$ Fifty one of the 78 women were managed by lumpectomy with or withor: irradiation, and seven of them developed recurrence at or close to the site of the initial lesions four to five months after surgery. Recurrences occurred in only two (7\%) of the 29 patients who received radiotherapy but in five of the 22 patients managed by lumpectomy alone. Treatment failed in two women: one was managed by mastectomy and died from breast cancer at 62 months, and the other was managed by lumpectomy and irradiation and was alive with disease at 86 months after initial presentation.

Roentgen's discovery of $x$ rays in 1895 led to their use in treating a wide range of malignant and benign conditions. Now radiotherapy is largely restricted to the palliation of symptoms in patients with advanced malignancy or to the cure of those with life threatening disease for whom other treatment either does not exist or is more toxic. Its use in benign disorders fell into disrepute because of potentially lethal late effects that may develop after treatment, in particular neoplasia induced by radiation. Regarding the breast, Read et al described the short term morbidity in 184 patients with small, primary breast tumours who were managed by lumpectomy and irradiation and commented on a $15 \%$ incidence of moderate skin erythema, a $56 \%$ incidence of mild to moderate breast discomfort, and a $9 \%$ incidence of pneumonitis. Of more serious concern are two reports that show a small but significant increase in mortality among patients with breast cancer managed by irradiation of the chest wall and mastectomy compared with those given only mastectomy, ${ }^{11}{ }^{12}$ a finding that became apparent only 